\title{
The Impact of the Greene County Juvenile Justice VIP (Victim Impact Panel) on Offender Development of Remorse and Empathy
}

\begin{abstract}
Aida Y. Hass, Samantha Lucas
Missouri State University, Springfield, USA

The incorporation of restorative justice philosophy and practice has become a fundamental component in the research literature on juvenile justice. The prospect of reducing criminal offending by providing opportunities for offenders to take responsibility and develop genuine remorse for their actions, as well as opportunities for the community to reconcile with the offender and provide greater support for both the perpetrator and victim after crime is promising. Rooted in the ideological principles of restorative justice, the VIP (victim impact panel) is designed to bring offenders face to face with victims of crime in order to develop a better sense of the harm and suffering that criminal behavior causes its victims. The current study explores the effect that participation in a VIP program has on juvenile offenders' perception of their criminal behavior and their development of remorse and empathy towards their victims.
\end{abstract}

Keywords: VIP (victim impact panel), restorative justice, re-integrative shaming, juvenile justice

\section{Introduction}

Restorative justice is a growing phenomenon that seeks to meet the needs of offenders, victims, and communities after a crime has been committed, by focusing attention on repair and social reintegration through the use of facilitated processes such as mediations, family group conferences, and VIPs (victim impact panels) (Zehr, 2005; Umbreit \& Armour, 2010). As restorative programs continue to gain ground within the criminal justice system, more community organizations committed to restorative justice values and initiatives are collaborating with traditional justice agencies and offices. In a broad sense, restorative justice addresses crimes as conflicts and attempts to restore autonomy to victims and offenders by engaging them directly in the process of determining just responses to criminal offenses (Wright, 2001). Rather than imposing punishment on the offender for a violation of law, restorative processes focus on repairing the harm of the offense and allowing those involved and impacted to mutually agree upon how the offender can best compensate and/or restore his/her victim, community, and/or self (Zehr, 2005; Zehr, 2002; Edgar \& Newell, 2006).

Restorative justice also seeks to reduce criminal offending by providing opportunities for offenders to take responsibility and develop genuine remorse for their actions, as well as opportunities for the community to reconcile with the offender and provide greater support for both the perpetrator and victim after crime (Edgar \& 
Newell, 2006; Braithwaite, 2002). In fact, substantial empirical evidence indicates that victims, offenders, and communities all experience greater levels of satisfaction with restorative justice processes than they do traditional models, suggesting an implied failure of the traditional system to meet many of the personal and social needs created by crime (Braithwaite, 2003).

Restorative justice principles and practices within a juvenile justice setting advocate for the use of alternative and/or supplemental processes, beyond the retributive and rehabilitative justice policies typically utilized by the formal justice system, in order to meet the needs of victims, offenders, and their communities, as well as empower those directly involved in a criminal offense (Umbreit \& Armour, 2010). Unlike other models of criminal justice, restorative justice focuses its attention on the relationships harmed by crime and responds to criminal violations by asking how that harm can be repaired and the offender reintegrated back into the community (Zehr, 2002; Umbreit \& Armour, 2010). This is typically achieved by way of facilitated encounters that encourage dialog between offenders, victims, and community members (Umbreit \& Armour, 2010; Zehr, 2002; Sharpe, 1998). Goals specific to restorative practices include offender accountability, victim inclusion in the justice process, individualized and need-based outcomes, and victim/offender reintegration into the community (Sharpe, 1998).

While restorative practices differ in process and function, they share common goals and objectives such as crime prevention, healing, reconciliation, community strengthening, and offender accountability (Sharpe, 1998). Common values and characteristics are also shared which make these processes uniquely restorative. These characteristics can include voluntary participation in restorative processes, the active participation of community volunteers on reparative boards, and inclusion of the crime's victim and offender in the creation of a just response to the criminal act.

\section{VIP and Restorative Justice Theory}

The VIP is a restorative justice program which allows offenders to meet with surrogate victims of crime when the real victim is unable or unwilling to participate. During these meetings, victims speak about the crimes that were committed against them to the offender or sometimes a group of offenders. The panel of victims makes sure to discuss the impact that the crime had on their lives and answer any questions the offenders might have. VIPs are increasing in popularity due to their therapeutic, educational, and communicative benefits for all the parties involved, including the victim, offender, juvenile court, and community (Jackson, 2009). By bringing juvenile offenders face to face with victims of crime and listening to their real life experiences, the juvenile offender will develop a better sense of the harm and suffering that criminal behavior causes its victims (Lutwak, Panish, Ferrari, \& Razzino, 2001). Thus, a major goal of the VIP is to help the juvenile offender develop feelings of genuine remorse about their criminal behavior and empathy toward their victim.

VIPs are rooted in the ideological principles of restorative justice. While the term restorative justice can mean many things, this conceptual framework continues to evolve and take shape through the writings and practices of those committed to its promises and goals. That being said, however, we must concede that restoration, regardless of what is restored, refers to a process of transformation, a process of change. Restorative justice is about giving power back to individuals and communities after crime; it is about strengthening communities through processes of conflict resolution and reconciliation; it is about restructuring how we practice justice and how we support offenders and victims. 
The application of restorative justice principles in juvenile delinquency intervention is becoming increasingly popular in criminological research. While debating about crime and punishment is driven by political rhetoric and conservative solutions of past decades, restorative justice offers a fundamentally unique framework for conceptualizing the context of criminal offending. This framework elevates the role of crime victims by holding offenders directly accountable for their behavior and the victims of their actions. Beyond restoring the emotional and material losses of victims, there is an attempt to create a sense of moral responsibility and accountability within the offender that will instill the values of remorse, empathy, and obligation to community (Harris, 2003).

These principles are consistent with John Braithwaite's (1989) theory of re-integrative shaming. Drawing from several existing theories such as subcultural, control, strain, labeling, and differential association, re-integrative shaming theory contends that shaming, if coupled with community reintegration, can control crime rather than generate it and that criminal behaviors are criminal due to an offender's conscious choice to act in defiance to his/her community values and/or social code (Braithwaite, 1989). According to Braithwaite (2003), the experience of guilt and shame are critical emotions that increase feelings of remorse and therefore play an important role in the desistence of criminal behavior. Remorse is seen as inhibiting delinquency by internally altering the juvenile's conscience through the experience of external social disapproval. Beyond the threat of official punishment, the juvenile who experiences re-integrative shaming will consider the loss of status, respect, and affection that goes along with social disapproval.

Effective accountability measures are seen as the cornerstone of re-integrative shaming theory. In a setting of social disapproval rituals, the juvenile offender can reflect on the harmful behavior they have caused by understanding its impact on their victim and relating to their pain. This will in turn create feelings of remorse and repentance that will encourage the offender to repair the harm they have caused and desist from future offending behavior. Bonds of mutual respect continue to be sustained and the offender's potential for restoration to full citizenship is not compromised (Jackson, 2009). Thus, social disapproval is conveyed in a setting that reconciles between the youth's unacceptable behavior and their potential for positive social reintegration. At the same time, through the experience of being confronted by victims of crime, offenders can begin to both cognitively and morally understand the extent of the harm they have caused and begin to take steps towards reconciliation. The likelihood of reoffending is then significantly reduced (Braithwaite, 2002).

\section{VIPs and the Development of Remorse and Empathy}

Remorse and empathy are the emotional foundation upon which VIPs are designed. Empathy is defined in the literature as "the ability to understand and share in another's emotional state or context" (Cohen \& Strayer, 1996, p. 988). In developing a victim empathy program for juveniles, Wallis, Aldington, and Liebmann (2009) defined empathy as a process of feeling for another person, and noted that there are three dimensions of empathy: cognition, affect, and behavior (Wallis et al., 2009). Cognitive empathy involves an understanding of another person's feelings, while affective empathy involves the sharing of another's emotional state. The behavioral component of empathy involves a conscious decision to alter one's response patterns as a result of the development of cognitive and affective empathy.

While researchers note that the conceptualization of empathy is a complex task, there is general agreement that the experience of empathy involves a dimension of responsive distress whereby the individual experiences a state of anxiety upon hearing of the suffering or hurt of another (Jackson, Blackburn, Tobolowsky, \& Baer, 
2011).

Remorse is regarded as an essential component of reconciliation that opens the pathway toward acceptance of responsibility and accounting for harm from within as opposed to blaming externals controls (Marshall, Marshall, Serran, \& O’Brien, 2009; Tangney, 1991). Studies have shown that remorse develops from feelings of guilt whereby an individual negatively assesses their behavior against a set of standards (Lutwak et al., 2001). Individuals who experience guilt towards their behavior will make attempts in the future to guarantee that behavior does not happen again as they are more likely to relate to the victim on an emotional level. Thus, the guilt response initiates reparative actions due to its internal focus (Harris, 2003). Moreover, empathy is described as being derived from the emotional feeling of guilt. Jackson et al. (2011) noted that "Through guilt, the transgressor is able to self-reflect and empathize with the victim. This also allows the transgressor to understand his or her role in the causing of harm, which may reduce his or her chances of placing blame on the victim or society at large. Individuals who are guilt-prone are more likely to experience empathy and can begin to understand the true extent of the harm” (Jackson et al., 2011, p. 10).

The role of empathy enhancement as an essential component of rehabilitative intervention has been well established in the empirical literature (Schiff, 1998; Sharpe, 1998; Bazemore \& Walgrave, 1999). Numerous studies have been conducted to assess the relationship between levels of empathy and criminal offending. The overwhelming finding is that individuals who express lower levels of remorse and empathy are at a greater risk for developing patterns of criminal behavior (Jurkovic \& Norman, 1977; Tangney, 1990; Sprang \& Compton, 1998; Gilligan, 2003; Harris, Walgrave, \& Braithwaite, 2004; Palermo, 2012). Joliffe and Farrington (2004) conducted a meta-analysis of 34 studies on the relationship between empathy and criminal behavior. Their findings reveal that the relationship between low levels of empathy and criminal offending is strong for violent offenders (Joliffe \& Farrington, 2004). Moreover, in another study, Joliffe and Farrington (2006) found that lower level of empathy amongst juveniles is related to bullying behavior by both males and females. Similar findings in a study comparing male and female self-reported offending indicate that both males and females who admit to committing violent crimes have lower levels of empathy than similar cohorts who do not (Joliffe \& Farrington, 2007).

The literature on restorative justice theory and practice has consistently revealed a strong connection between the implementation of restorative justice programs that facilitate dialog, encourage reconciliation, mediate restitution, and enhance community reintegration, and the reduction of recidivism, particularly with regard to juvenile offenders (Bonta, Wallace-Capretta, Rooney, \& McAnoy, 2002; Bradshaw \& Roseborough, 2005; Latimer, Dowden, \& Muise, 2005; Nugent, Williams, \& Umbreit, 2004; Bergseth \& Bouffard, 2007). Researchers note that the need to evaluate the connection between correctional practices such as VIPs and the development of an emotional response (remorse and empathy) in offenders that will affect behavior warrants further empirical examination (Rojek, Coverdill, \& Fors, 2003).

In a study by Jackson and Bonacker (2006), researchers examined the effects of the Missouri Department of Corrections Restorative Justice Program's VIT (victim impact training) on the emotional development of guilt, shame and empathy amongst offenders (Jackson \& Bonacker, 2006). A regression analysis utilizing a panel design approach revealed a significant relationship between shame and empathy among offenders participating in the VIT. Moreover, VIT participants were less likely to recidivate than the comparison control group of non-participants. In another study, Schaaf (2008) examined the effects of VIPs on DWI (driving while intoxicated) offenders. An analysis of pre and post questionnaires of 61 participating offenders revealed that 
there was a significant increase in empathy scores after attending the VIP (Schaaf, 2008). Moreover, an examination of data on juvenile offenders participating in Australia's RISE (Re-integrative Shaming Experiments) reveals positive changes in the attitudes of offenders with regard to their feelings of repentance and desire to repay the victim and society (Kim \& Gerber, 2011).

Programming aiming at reducing the recidivism rate of criminal offending is indeed the cornerstone of evidence based policy and practice. Equally important, however, is the evaluation of intervention strategies in terms of their restorative impact on both victim and offender. It is therefore imperative to further assess the relationship between the implementation of restorative justice practices such as VIPs within juvenile justice, and the socio-cognitive development of remorse and empathy as mediating variables in the desistence of juvenile delinquency.

\section{The Use of VIPs in Greene County Juvenile Justice: A Case Study}

\section{Background}

Amidst the goal of achieving restoration and balance within the implementation of juvenile justice strategies is the discussion of programming aiming at increasing empathy towards victims of crime. Juvenile justice professionals have time and again note the powerful effects of hearing the first-hand experiences of how crime not only affects the victim, but their surrounding network of family, friends, and community (Bergseth \& Bouffard, 2007). While variations exist in the application of VIPs throughout various juvenile justice systems nationwide, one common theme permeates: the heart-felt, often emotional communication of the financial, emotional, and physical impact of crime on its victims, to an audience of listening offenders. Thus, the images of real people, with real stories of their pain and suffering due to crime, will be imprinted on the offender's mind, with the hope that these images will allow reflection on the damaging effects of crime and serve to support the offender's efforts to change his or her behavior.

In March of 2007, the CDR (Center for Dispute Resolution) at Missouri State University partnered with the Greene County Juvenile Justice Office in Springfield, Missouri, to launch the first VOM (Victim-Offender Mediation) program. Through this collaboration, volunteers are trained to facilitate meetings between juvenile offenders and their victims. During these face-to-face encounters, the victim and the offender have the opportunity to talk to one another about the crime committed, how this event has impacted their lives, and various ways that restitution can be made. Juveniles eligible to participate in this program are first or second time offenders convicted of property crimes and minor assaults.

VIPs were originally developed to provide youth who were referred to the VOM program, but whose victims were not willing to participate, with a similar experience. Offenders participating in the VIP do not meet with their direct victims, but rather are part of an audience of offenders who listen to the stories of "surrogate" victim presenters who recall their stories of how crime has affected them. The VIP program currently also services youth who are direct referrals from Juvenile Court.

The Greene County Juvenile Justice VIP program provides youth offenders with a vivid glimpse of the impact of crime on its victims. It employs a unique approach that goes beyond the traditional implementation of VIPs where offenders are part of a passive audience, to actively engage the juveniles in a meaningful dialogue. The goal is to provide a safe environment that creates a context which encourages youth offenders to reflect on their actions and become more empathetic towards crime victims by actually "seeing" the long-term consequences of their behavior. Victim panelists are prepared in advance to tell their stories and describe their 
experiences as victims of crime in an impactful way. Juvenile participants are required to listen attentively and respectfully, but are also encouraged to ask questions and talk to the panel of victims. Youth participating in the VIP are broken down into groups of two to five and are required to meet with a program facilitator from the CDR prior to attending the panel. During this meeting, they discuss how the VIP program works, what to expect, and how to behave during the panel presentation. The parents of these groups meet in a separate room with staff who answer any questions they may have about the program.

VIPs are held every other month at the CDR. They run about 20 to 30 minutes per victim-presenter and there are typically two presenters on each panel. On average, about 10 to 15 juvenile offenders are referred to each VIP program. Following the VIP meeting, youth participants are required to reflect on what they have seen and learned through this experience in a written essay describing their participation in the panel. They are given a week to turn in their paper to the Juvenile Office.

\section{Methodology}

The goal of this study was to explore the effect that participation in a VIP program has on juvenile offenders' perception of their criminal behavior and their development of remorse and empathy towards their victims. In order to accomplish this task, a qualitative research methodology was employed, using the techniques of a pre-test questionnaire combined with a post participation analysis of the offenders' written essays. This approach was used to optimize the data that we were able to access. Because the majority of juvenile participants in this study were not required to meet again with their probation officer following the VIP, it was not possible to conduct a follow-up interview or focus group meeting. Therefore, the post-participation analysis of the written essays served as an empirical inquiry within a real-life context that allowed us to examine the juvenile offenders' reaction to the VIP, and to compare their thoughts and feelings after that experience, with their thoughts and feelings prior to participating in the VIP.

Qualitative research methodologies are the hallmark of understanding human interactions, perceptions, and personal experiences (Miller \& Tewksbury, 2006). A qualitative design also acknowledges the process of discovery and inductive progression in a manner that would be difficult to achieve through quantitative research (Leavy, 2009). Gaining an in-depth, insightful perspective on juvenile offenders' reactions to their interaction with victims of crime during the VIP process is therefore best achieved through a focused approach that can bring the researchers as close as possible to their subjects and their experiences (Krueger \& Casey, 2000). In doing this, we hoped to become better informed of their personal feelings, emotions, and struggles as expressed in their written dialogue.

The pre-test questionnaire used for this study was designed to evaluate the juvenile offenders' trait emotions of remorse and empathy prior to participating in the VIP program. The structure of the questionnaire focused on whether or not the juvenile was currently experiencing feelings of personal wrongdoing as reflected in measures of guilt, shame, and empathy. A 20-item five-point Likert Scale questionnaire (see Appendix A) was developed using items from the SSGS (state shame and guilt scale) (Tangney \& Dearing, 2003) as well as the basic empathy scale (Joliffe \& Farrington, 2006), with a distribution of questions reflecting both constructs. Questions were selected based on prior research showing the greater reliability of items that reflect specific emotions rather than those that ask about emotions in general (Schaaf, 2008). A statistical analysis of response distribution was conducted to assess the offenders' personal experiences and perceptions prior to participating in the VIP. 
In addition, a validation exercise was conducted prior to the administration of the questionnaire to the study group. The instrument was distributed in a group setting by the researchers to 8 juvenile offenders at the Greene County Juvenile Academy, a 90-day residential program for juvenile offenders who are involved with the Greene County Juvenile Court. Our study group included one female and eight male juveniles ages 15-17. Our goal was to get feedback from a similar cohort of youth in order to determine whether the questions were asked in a manner that they could understand. Through this exercise, revisions were made to the questionnaire that reflected their suggestions for better, more straightforward wording and the use of terminology that was more comprehensible to young people.

In order to assess post-VIP participation changes in offender attitudes and perceptions with regard to crime, victimization and perceptions of remorse and empathy, we analyzed the written reaction essay that is a requirement of each juvenile participant. This served as a useful technique in helping us gain a better understanding of the thoughts, insights, and encounters of our research participants (Lindlof \& Taylor, 2002). Our analysis used a guided approach that searched for emerging sequences of thought, thematic trends, and recurrent patterns in the use of words and expression that reflected the attitudes and feelings of the research subjects (Patton, 2002; Fife, 2005). This allowed us to objectively and systematically evaluate the experiences of the juvenile offenders participating in the VIP, and determine their thoughts, feelings, and attitudes about what they observed, in order to assess its potential impact in increasing remorse and empathy.

Data collection for this research study took place on the first night of the November VIP at the CDR in Springfield, MO. The first night involves an orientation session where the juveniles participating in the VIP are given more information about the program, how it will work, and what is expected out of them. There were 12 juveniles present, along with their parents and/or guardians. There were seven males and five females. They were all first time offenders, convicted of nonviolent, mostly property crimes such as shoplifting, property damage, and trespassing. The majority of juvenile offenders referred to the VIP program are classified as "informal adjustment", the lowest level of supervision in Greene County Juvenile Justice. During this orientation, the research study was described to the juvenile participants, as well as to their parents/guardians. Program facilitators were previously informed of our research design and implementation through discussions meetings between the researchers CDR staff. After the research study was explained and questions answered, written consent was obtained from both the juvenile and his/her parent or guardian, and the pre-test questionnaire was administered to the juvenile participants (see Appendix B). Of those juveniles at the orientation meeting, 11 volunteered to participate in the study.

Following the actual VIP, participating juvenile offenders had to write a reaction essay describing their experience listening to and interacting with the victim panelists. This essay had to be turned in to the offender's probation officer for review, within one week of the panel meeting. The essays were collected by the Greene County Juvenile Office, and mailed to us for further study.

\section{Findings}

The frequency distribution of responses to the 20-item pre-test questionnaire revealed various trends in the arrangement of values to each item assessing guilt, shame, and empathy. In order to simplify the presentation of data, the scaled responses were distributed into two categories, with responses 1 and 2 representing disagreement with the statement, and responses 3, 4, and 5 representing agreement with the statement. The following table provides a summary of the distribution of responses, indicating the percentage of juvenile 
offenders agreeing with the statement, and the percentage of survey respondents disagreeing with the statement (see Table 1).

Table 1

Pre-Test Questionnaire

\begin{tabular}{|c|c|c|c|}
\hline Item & & $\begin{array}{l}\text { Agree } \\
N=11(\%)\end{array}$ & $\begin{array}{l}\text { Disagree } \\
N=11(\%)\end{array}$ \\
\hline \multicolumn{4}{|c|}{ Self-oriented shame } \\
\hline 4 & I feel that I am of little value & 18.2 & 91.8 \\
\hline 12 & I feel worthless & 9.1 & 90.9 \\
\hline 2 & I wish I could disappear & 9.1 & 90.9 \\
\hline 1 & I don’t feel good about myself & 18.2 & 81.8 \\
\hline 6 & I feel like I am a bad person & 36.4 & 63.6 \\
\hline 3 & I feel remorseful & 36.4 & 63.6 \\
\hline 9 & I feel humiliated & 45.4 & 54.6 \\
\hline 8 & I feel proud & 27.2 & 72.8 \\
\hline \multicolumn{4}{|c|}{ Self-oriented guilt } \\
\hline 7 & I cannot stop thinking about something bad I have done & 45 & 54.6 \\
\hline 5 & I feel tension about something I have done & 63.6 & 36.4 \\
\hline 10 & I feel like apologizing for something bad I have done & 72.5 & 27.2 \\
\hline 11 & I feel pleased about something I have done & 37.3 & 63.7 \\
\hline 13 & I feel bad about something I have done & 63.6 & 36.4 \\
\hline \multicolumn{4}{|c|}{ Other-oriented guilt/shame } \\
\hline 16 & I feel like I can’t be loved because of the offense I have done & 18.2 & 81.8 \\
\hline 15 & I feel like I'm now part of a group of people society looks down upon & 27.3 & 72.7 \\
\hline 14 & I feel others would treat me differently if they knew about my offense & 36.4 & 63.6 \\
\hline \multicolumn{4}{|c|}{ Empathy } \\
\hline 17 & I feel that my offense really hurt someone & 63.6 & 36.4 \\
\hline 18 & I feel sad when I see that other people are sad & 63.6 & 36.4 \\
\hline 19 & I feel that I understand how another person feels when they are hurt & 72.7 & 27.3 \\
\hline 20 & I feel that my actions can affect other people & 100.0 & 00.0 \\
\hline
\end{tabular}

The pre-test questionnaire was designed to measure the offender's self-conscious emotions by conceptualizing self-oriented feelings of guilt and shame as reflected in items 1 through 13 . Items 14, 15, and 16 measured other-oriented feelings of guilt and shame, attempting to assess self through the offender's perception of how others feel about them. The remainder of the items was designed to give each juvenile offender the opportunity to reflect on their perception of self with regard to the feelings of others in an effort to establish their potential for empathy.

The distribution of responses indicates that, with the exception of Item 8, the overwhelming majority of juvenile offenders scored low on the various trait measures of shame, with the highest number (91.8\%) attributed to Item \#4, "feeling of little value”, followed by $90.9 \%$ denying "feeling worthless" or "wishing they could disappear". Items measuring guilt seemed to paint a different picture, with findings suggesting that most of the juveniles in our study do indicate feelings of regret, as indicated by $72.5 \%$ of respondents feeling they "need to apologize for something bad they have done", and 63.6\% "feeling bad about something they have done". However, with regard to items measuring feelings of guilt and shame based on the perception of treatment by others, responses suggest that whatever feelings of guilt juveniles are experiencing did not impact 
their feelings of how others will treat them, indicating a discrepancy in the moral evaluation of their behavior.

Respondents' reflection on questionnaire items measuring empathy indicates that their evaluation of self includes an understanding of how their actions can affect other people, with $100 \%$ of juveniles indicating agreement with item \#20, "I feel that my actions can affect other people”. With reference to their particular crime, however, over $36 \%$ of juvenile respondents indicated that they did not feel that "their offense hurt someone", reflecting a distinction between the presence of cognitive empathy and the development of affective empathy.

A close analysis of the content within the written reaction essays of the juveniles revealed several recurrent patterns of expression surrounding various themes. In a broad sense, all of the juvenile participants in the VIP uniformly described the program as helpful, as expressed in the following poignant quotations from their reaction essays:

This experience has changed my views on my behavior.

As a result of this class, I will think about my actions.

This program is more than just a "get out of jail free" card.

The VIP program has helped me both mentally and physically.

A collective examination of the written reaction essays with regard to self-oriented shame indicated the expression of three emerging themes:

Committing a crime is humiliating to yourself and your family.

I am embarrassed at my actions.

I feel bad for putting my family through this.

An analysis of the written reaction essays also indicated that the juvenile offenders expressed self-oriented guilt, as articulated through the various statements surrounding the following themes:

I need to apologize for hurting others.

This is a good way to make up for my wrong.

My actions are regretful.

With regard to developing a sense of other-oriented guilt/shame, the reaction essays showed the emergence of two themes indicating that they have a better understanding of how the reaction of others affects their own self-concept:

People look down on you when you hurt others.

I now see why my family is disappointed in my behavior.

With respect to written expressions within the reaction essays that reveal empathy enhancement, the juvenile offenders seemed to communicate a better understanding of the concept of empathy as more than just understanding another individual's feelings in the following themes:

I need to think about the consequences of my behavior on others and not just for myself.

Crime always hurts people; the people affected by crime are real.

You should be sympathetic to your victim... crime is very personal.

\section{Discussion}

The goal of the VIP as a rehabilitative intervention is to provide offenders with clear evidence that their actions not only affects them but also affects others as well. Through the presentation of this evidence, 
offenders are able to take the perspective of victims of crime, and therefore be able to better understand the impact of their own actions. The findings from this case study of juvenile participants in a VIP program suggest that this method of criminal justice intervention has the potential to enhance the offender's understanding of the concept of empathy and help develop their moral evaluation of offending behavior.

An examination of the pre-test questionnaire indicated that the majority of juvenile respondents scored low on items measuring the emotional feelings of shame, indicating a lack of moral self-judgment in the evaluation of their behavior. On the contrary, a significant number of the juveniles indicated a sense of apology and regret, reflecting some emotional feeling of guilt towards their actions. These findings are consistent with studies that discern between the cognitive states of guilt and shame as mediating the type of self-conscious state necessary to affect the desistence of future offending behavior (Tibbetts, 2003; Tangney, Youman, \& Stuewig, 2009). The distinction between shame and guilt centers upon the difference in focus between a reflection on the self and a reflection on behavior (Tangney, Stuewig, \& Hafez, 2011). Compelling findings in the literature suggest that the presence of both emotional states have a strong impact on offending behavior, and that both shame and guilt should be considered in the intervention of criminal justice sanctioning (Hosser, Windzio, \& Greve, 2008).

In this study, juveniles indicated a negative evaluation when focusing on their particular "bad" behavior. However, when reflecting on themselves as individuals, there was no indication of a negative judgment of self. From this perspective, the differential evaluation indicates that the juvenile offenders are detaching their behavior from themselves so that they are not the object of judgment, in order to protect their core identity. According to the emerging themes in the post-VIP participation reaction essays, however, juvenile participants indicated an increase in their scrutiny of self, and the potential for actions to produce cognitive states of humiliation and embarrassment, and the negative evaluation by others as reflected in their disapproval and disappointment. This finding is consistent with the development of shame as more linked to the public exposure of disapproving others. The following quotes from the reaction essays emphasize this point:

The people that had crimes committed to them, I really felt bad for the things they had to say. I pretty much almost cried.

I actually think this program is helping, because it helped me comprehend that I need to change. I'm actually hurting people.

This program has changed ME so much.

After hearing (victim's) story and seeing how forgiving he was...it wanted to make me a better person; clean up my act before it was too late.

Notably, however, the goal of criminal justice intervention is not to merely expose offenders to collective disapproval, as this alone can contribute to a global judgment of failure and the assessment of self as unchangeable (Stuewig, Tangney, Heigel, Harty, \& McCloskey, 2010). The experience of shame alone can lead to anger and resentment with a marked proneness to blame others, thereby countering the potentially positive effects of treatment (Bear et al., 2008).

The VIP experience, on the contrary, is designed to be re-integrative, rather than stigmatizing, where the goal is to instill feelings of shame that arise from a focus on condemning the criminal act as irresponsible and bad, and not on the individual, who is given the chance for acceptance through reparative action. Thus, consistent with Braithwaite's theory, the VIP is designed to increase feelings of guilt and remorse through the process of re-integrative shaming. An examination of the reaction essays of the juvenile participants indicated a recurrent theme of regret whereby the majority of offenders expressed a desire to apologize and make up for 
their wrongful behavior towards their victims. The following quotes emphasize this thematic trend:

Although I had already realized that what I did was wrong, this really opened my eyes and made me think about how much the items I took could have meant to that store. I would give anything just for them to know that if I could take it back, I would in a heartbeat.

If you did anything against anybody, apologize.

If I could rewind in time I would change everything that happened that day and never would have been in this situation.

This is a shot at setting straight what you know you did wrong.

Tonight was full of regretful actions.

With regard to the effect of participation in the VIP program on offender perception of empathy, emerging themes within the juvenile respondents' reaction essays indicate a better articulation of affective empathy. Of significance, prior to listening to, observing, and interacting with the victims of crime on the VIP, a third of the juvenile offenders in the study indicated that they did not feel that their criminal actions actually hurt anyone, despite the fact that all of the offenders in the study communicated an understanding that their actions can affect other people. The presence of cognitive empathy indicates an awareness of another's emotions as a mechanism of perspective taking. This is akin to putting yourself in someone else's shoes and being able to identify with their emotional state, without actually experiencing those emotional states. Affective empathy, on the contrary, is the ability to not only recognize the emotions by imagining oneself in that situation, but to actually feel the emotional state of another human being while recognizing that they are not your own (Jones et al., 2009).

Numerous findings suggest greater deficits in affective empathy as a contributing factor in the prevalence and persistence of criminal behavior (Jones et al., 2009; Anastassiou \& Warden, 2008; Joliffe \& Farrington, 2007; de Vignemont \& Singer, 2006). Thus, addressing both the cognitive and affective components of empathy is essential in the treatment of juvenile offenders, in order to align elements of behavioral and internal change. An examination of the post-participation reaction essays, with specific focus on those juveniles who scored lowest on the measure of affective empathy indicated an internalized understanding of the feelings of the victims that goes beyond the conceptualization of the emotional state. The following quotes from the post-participation reaction essays of juvenile offenders underscore this point:

As I listened... I felt her pain... I could only imagine how much that (plant) meant to her and to have it stolen, is that much worse.

Now I really understand how my behavior can affect peoples’ lives in a big way.

By listening to our speaker, I could better connect with the victims.

Taking something from somebody could be easy for you, but it could be heartbreaking for them.

This program was very helpful in my opinion in order to help think about who could be hurt in many different situations like cases similar to mine.

No matter what the situation is that in the end of it all it will always hurt somebody.

\section{Conclusion: A Call for Further Research}

The results from our exploratory study of a group of juvenile offenders participating in a VIP program indicate that the development of empathy is a strong component of the VIP process. While the role of empathy in the desistance of future offending behavior warrants further examination, a practical and theoretical need for the incorporation of empathy-enhancing programming in the criminal justice intervention with offenders 
convicted of crime is essential. The development of affective empathy as a moral emotion is amenable to therapeutic treatment and should therefore become an optimal goal of justice sanctions programs designed to modify and enhance an offender's cognitive-behavioral states.

Moreover, the potential for empathy enhancement to reduce offending behavior also calls into consideration the need to incorporate preventative measures that target at risk individuals before criminal behavior occurs. Future research endeavors must direct attention to developing strategies to implement empathy enhancing programs and curriculum, possibly at the school level, that would increase the awareness of the effects of an individual's behavior and actions on the lives of other people.

The findings from this study open the door for a more large scale evaluation of the long-term effect of the VIP program on the attitude and behavior of juvenile offenders. The immediate effects of participation in a VIP provide compelling evidence for its potential to increase empathy for victims of crime. While the finding can be generalized to a broader cohort of juvenile offenders, they are nevertheless limited by the small research sample and implications for policy evaluation would benefit from a more large scale study that would also provide a significant longitudinal analysis of the behavior of juvenile participants in the VIP program in order to assess its long-term impact.

Finally, the findings from this study are consistent with the research literature with regard to the more positive effects of re-integrative shaming as a method of instilling responsibility to self and community. Thus, sentencing policies and practices designed to shame and humiliate offenders are considered counter-productive and should be restructured in a manner that would foster in the offender a more constructive and comprehensive feeling of guilt that directs attention to their behavior as impacting self , family, and community, while at the same time providing an opportunity for repentance, forgiveness, and redemption.

\section{References}

Anastassiou-Hadjicharalambous, \& Warden. (2008). Cognitive and affective perspective-taking in conduct-disordered children high and low on callous-unemotional traits. Child and Adolescent Psychiatry and Mental Health, 2, 16.

Ashworth, A. (2002). Responsibilities, rights and restorative justice. The British Journal of Criminology, 42, 578-595.

Bazemore, G., \& Walgrave, L. (1999). Restorative juvenile justice: Repairing the harm of youth crime. Monsey, N.Y.: Criminal Justice Press.

Bear, G., Uribe-Zarain, X., Manning, M. A., \& Shiomi, K. (2008). Shame, guilt, blaming, and anger: Differences between children in Japan and the US. Motivation and Emotion, 33, 229-238.

Bergseth, K. J., \& Bouffard, J. A. (2007). The long-term impact of restorative justice programming for juvenile offenders. Journal of Criminal Justice, 35, 433-451.

Bonta, J., Wallace-Capretta, S., Rooney, J., \& McAnoy, K. (2002). Anoutcome evaluation of a restorative justice alternative to incarceration. Contemporary Justice Review, 5(4), 319-338.

Bradshaw, W., \& Roseborough, D. (2005). Restorative justice dialogue: The impact of mediation and conferencing on juvenile recidivism. Federal Probation, 69(2), 15-21.

Braithwaite, J. (1989). Crime, shame and reintegration. Cambridge: Cambridge University Press.

Braithwaite, J. (2002). Restorative justice and responsive regulation. New York, N.Y.: Oxford University Press.

Braithwaite, J. (2003). Principles of restorative justice. In A. von Hirsch, J. Roberts, A. E. Bottoms, K. Roach, \& M. Schiff (Eds.), Restorative justice \& criminal justice: Competing or reconcilable paradigms? (pp. 1-20). Portland, O. R.: Hart Publishing.

Center for Dispute Resolution. (2012). Restorative justice programs: Victim impact panel program for youth. Retrieved June 20, 2012, from http://www.missouristate.edu/cdr/VIP.htm

Coben, J., \& Harley, P. (2004). Intentional conversations about restorative justice, mediation, and the practice of law. Journal of Public Law and Policy, 25(2), 235-334. 
Cohen, D., \& Strayer, J. (1996). Empathy in conduct-disorder and comparison youth. Developmental Psychology, 32, 988-998.

Darley, J. M., \& Pittman, T. S. (2003). The psychology of compensatory and retributive justice. Personality and Social Psychology Review, 7(4), 324-336.

de Vignemont, F., \& Singer, T. (2006). The empathic brain: how, when and why? Trends in Cognitive Sciences, 10, 435-441.

Duff, A. (2003). Restoration and retribution. In A. von Hirsch, J. Roberts, A. E. Bottoms, K. Roach, \& M. Schiff (Eds.), Restorative justice \& criminal justice: Competing or reconcilable paradigms? (pp. 3-59). Portland, O. R.: Hart Publishing.

Fife, W. (2005). Doing fieldwork: Ethnographic methods for research in developing countries and beyond. New York: Palgrave Macmillan.

Gilligan, J. (2003). Shame, guilt, and violence. Social Research, 70, 1149-1180.

Greene County. (2012). Victim impact panels. Retrieved from http://www.greenecountymo.org/juvenile/vic_wit_impact_panel. php

Greene County. (2012). Victim offender mediation. Retrieved from http://www.greenecountymo.org/juvenile/vic_wit_mediation. php

Gromet, D. M., \& Darley, J. M. (2009). Punishment and beyond: Achieving justice through the satisfaction of multiple goals. Law \& Society Review, 43(1), 1-37.

Harris, N., Walgrave, L., \& Braithwaite, J. (2004). Emotional dynamics in restorative conferences. Theoretical Criminology, 8, 191-210.

Harris, N. (2003). Reassessing the dimensionality of the moral emotions. British Journal of Psychology, 94, 457-473.

Harris, N., Walgrave, L., \& Braithwaite, J. (2004). Emotional dynamics in restorative conferences. Theoretical Criminology, 8 , 191-210.

Herman, S., \& Wasserman, C. (2001). A role for victims in offender reentry. Crime \& Delinquency, 47(3), 428-445.

Hosser, D., Windzio, M., \& Greve, W. (2008). Guilt and shame as predictors of recidivism: A longitudinal study with young prisoners. Criminal Justice and Behavior, 35, 138-152.

Jackson, A. L., Blackburn, A. G., Tobolowsky, P., \& Baer, D. (2011). An examination of guilt, shame, empathy and blaming among a sample of incarcerated male and female offenders. The Southwest Journal of Criminal Justice, 8(1), 1-29.

Jackson, A. L., \& Bonacker, N. (2006). The effect of victim impact training on the development of guilt, shame, and empathy among offenders. International Review of Victimology, 13, 45-69.

Jackson, A. L. (2009). The impact of restorative justice on the development of guilt, shame, and empathy among participants in a victim impact training program. Victims and Offenders, 4, 1-24.

Jolliffe, D., \& Farrington, D. P. (2004). Empathy and offending: A systematic review and meta-analysis. Aggression and Violent Behavior, 9, 441-476.

Jolliffe, D., \& Farrington, D. P. (2006). Examining the relationship between low empathy and bullying. Aggressive Behavior 32(6), 540-550.

Jolliffe, D., \& Farrington, D. P. (2006). Development and validation of the basic empathy scale. The Journal of Adolescence, 29(4), 540-550.

Jolliffe, D., \& Farrington, D. P. (2007). Examining the relationship between low empathy and self-reported offending. British Pscyhological Society, 12(2), 265-286.

Jones, A. P., Larsson, H., Ronald, A., Rjisdijk, F., Busfield, P., McMillan, A., et al. (2009). Phenotypic and aetiological relationships between psychopathic tendencies, autistic traits, and emotion attribution. Criminal Justice and Behavior, 36, 1198-1212.

Krueger, R. A., \& Casey, M. A. (2000). Focus groups: A practical guide for applied research (3rd ed.). Thousand Oaks, C.A.: Sage.

Latimer, J., Dowden, C., \& Muise, D. (2005). The effectiveness of restorative justice practices: A meta-analysis. Prison Journal, 85(2), 127-144.

Leavy, P. (2009). Method meets art: Art-based research practice. New York, N.Y.: The Guilford Press.

Levrant, S., Cullen, F. T., Fulton, B., \& Wozniak, J. F. (1999). Reconsidering restorative justice: The corruption of benevolence revisited? Crime \& Delinquency, 45(1), 3-27.

Lindlof, T. R., \& Taylor, B. C. (2002). Qualitative communication research methods. Thousand Oaks, C.A.: Sage.

Lutwak, N., Panish, J. B., Ferrari, J. R., \& Razzino, B. F. (2001). Shame and guilt and their relationship to positive expectations and anger expressiveness. Adolescence, 36(144), 641-643. 
Jackson, A., \& Bonacker, N. (2006). The effect of victim impact training on the development of guilt, shame, and empathy among offenders. International Review of Victimology, 13, 45-69.

Jackson, A. L. (2009). The impact of restorative justice on the development of guilt, shame, and empathy among participants in a victim impact training program. Victims and Offenders, 4, 1-24.

Jurkovic, G. J., \& Norman, M. (1977). Relation of moral and cognitive development to juvenile delinquency. Journal of Abnormal Psychology, 86(4), 414-420.

Kim, H. J., \& Gerber, J. (2011). The effectiveness of reintegrative shaming and restorative justice conferences: Focusing on juvenile offenders' perceptions in australian reintegrative shaming experiments. International Journal of Offender Therapy and Comparative Criminology, 56(7), 1063-1079.

Marshall, W. L., Marshall, L. E., Serran, G. A., \& O’Brien, M. D. (2009). Self-esteem, shame, cognitive distortions and empathy in sexual offenders: Their integration and treatment implications. Psychology, Crime \& Law, 15(2 \& 3), 217-234. Retrieved from http://www.informaworld.com

McDowell, L. A., \& Whitehead, J. T. (2009). Varieties of restorative justice: Therapeutic interventions in context. In D. Polizzi, \& M. Braswell (Eds.), Transforming corrections: Humanistic approaches to corrections and offender treatment (pp. 149-170). Durham, N. C.: Carolina Academic Press.

Miller, S. (2011). After the crime: The power of restorative justice dialogues between victims and violent offenders. New York, N.Y.: New York University Press.

Miller, J. M., \& Tewksbury, R. (2006). Preface. In J. M. Miller, \& R. Tewksbury (Eds.), Research methods: A qualitative reader (pp. vii-viii). Upper Saddle River, N.J.: Pearson Prentice Hall.

Mosher, D. L., \& Mosher, J. B. (1967). Guilt in prisoners. Journal of Clinical Psychology, 23(2), 171-173.

Newell, T. (2000). Forgiving justice: A quaker vision for criminal justice. London: Quaker Home Service.

Nugent, W., Williams, M., \& Umbreit, M. (2004). Participation invictim-offender mediation and the prevalence of subsequent

delinquent behavior: A meta-analysis. Research on Social Work Practice, 14(6), 408-416.

Okimoto, T.G., Wenzel, M., \& Feather, N.T. (2009). Beyond retribution: Conceptualizing restorative justice and exploring its determinants. Social Justice Research, 22, 156-180.

Palermo, G. B. (2012). Moral reasoning and recidivism in young sex offenders. International Journal of Offender Therapy and Comparative Criminology, 56(7), 983-985.

Patton, M. Q. (2002). Qualitative research and evaluation methods. Thousand Oaks, C.A.: Sage.

Pranis, K. (2005). The little book of circle processes: A new/old approach to peacemaking. Intercourse, P.A.: Good Books.

Pranis, K., Stuart, B., \& Wedge, M. (2003). Peacemaking circles: From crime to community. St. Paul, M. N.: Living Justice Press.

Prichard, J. (2010). Net-widening and the diversion of young people from court: A longitudinal analysis with implications for restorative justice. The Australian and New Zealand Journal of Criminology, 43(1), 112-129.

Robinson, R., Roberts, W. L., Strayer, J., \& Koopman, R. (2007). Empathy and emotional responsiveness in delinquent and non-delinquent adolescents. Social Development, 16(3), 555-579.

Rojek, D. G., Coverdill, J. E., \& Fors, S. W. (2003). The effect of victim impact panels on DUI re-arrest rates: A five-year follow-up. Criminology, 41(4), 1319-1340.

Schaaf, K. (2008). Empathy: Victim impact panels and DWI offenders. UW-L Journal of Undergraduate Research, XI.

Sharpe, S. (1998). Restorative justice: A vision for healing and change. Edmonton, Alberta: Edmonton Victim Offender Mediation Society.

Schiff, M. F. (1998). Restorative justice interventions for juvenile offenders: A research agenda for the next decade. Western Criminology Review, 1(1). Retrieved from http://wcr.sonoma.edu/v1n1/schiff.html

Sprang, G., \& Compton, R. (1998). Victim impact panels: An examination of the effectiveness of this program lowering recidivism and changing offenders' attitudes about drinking and driving. Journal of Social Service Research, 22, 73-84.

Stuewig, J., Tangney, J. P., Heigel, C., Harty, L., \& McCloskey, L. (2010). Shaming, blaming, and maiming: Functional links among the moral emotions, externalization of blame, and aggression. Journal of Research in Personality, 44(1), 91-102.

Tangney, J. P. (1990). Assessing individual differences in proneness to shame and guilt: Development of the self-conscious affect and attribution inventory. Journal of Personality and Social Psychology, 59, 102-111.

Tangney, J. P. (1991). Moral affect: The good, the bad, and the ugly. Journal of Personality and Social Psychology, 61(4), 598-607.

Tangney, J. P., \& Dearing, R. L. (2003). Shame and guilt. New York, N.Y.: Guilford Press. 
Tangney, J. P., Youman, K., \& Stuewig, J. (2009). Proneness to shame and proneness to guilt. In M. R. Leary, \& R. H. Hoyle (Eds.), Handbook of individual differences in social behavior (pp. 192-209). New York, N.Y.: Guilford Press.

Tangney, J. P., Stuewig, J., \& Hafez, L. (2011). Shame, guilt, and remorse: Implications for offender populations. Journal of Forensic Psychiatry and Psychology, 22(5), 706-723.

Tibbetts, S. G. (2003). Self-conscious emotions and criminal offending. Psychological Report, 93(1), 101-126.

Umbreit, M., \& Armour, M. P. (2010). Restorative justice dialogue: An essential guide for research and practice. New York, N.Y.: Springer Publishing Company.

Valore, T. G., \& Siemen, K. A. (2003). Alternatives to punishment: Words and ice. Reclaiming Children and Youth, 12(2), 93-97.

Wallis, P., Aldington, C., \& Liebmann, M. (2009). What have I done?: A victim empathy programme for young people (pp. 1-204). London, Great Britain: Jessica Kingsley Publishers. Retrieved July 10, 2012, fromhttp://site.ebrary.com/lib/ missouristate/docDetail.action\

Wenzel, M., \& Thielmann, I. (2006). Why we punish in the name of justice: Just desert versus value restoration and the role of social identity. Social Justice Research, 19(4), 450-470.

Wright, M. (2001). Justice for victims and offenders: A restorative response to crime. Winchester, U.K.: Waterside Press.

Zehr, H. (2002). The little book of restorative justice. Intercourse, P.A.: Good Books.

Zehr, H. (2005). Changing lenses: A new focus for crime and justice. Scottdale, P.A.: Herald Press.

\section{Appendix A}

Directions: The following are some statements that may or may not describe how you are feeling RIGHT NOW. Please rate each statement using the 5 point scale below. Remember to rate each statement based on how you are feeling $\underline{\text { RIGHT AT THIS }}$ MOMENT.

1. I don’t feel good about myself.

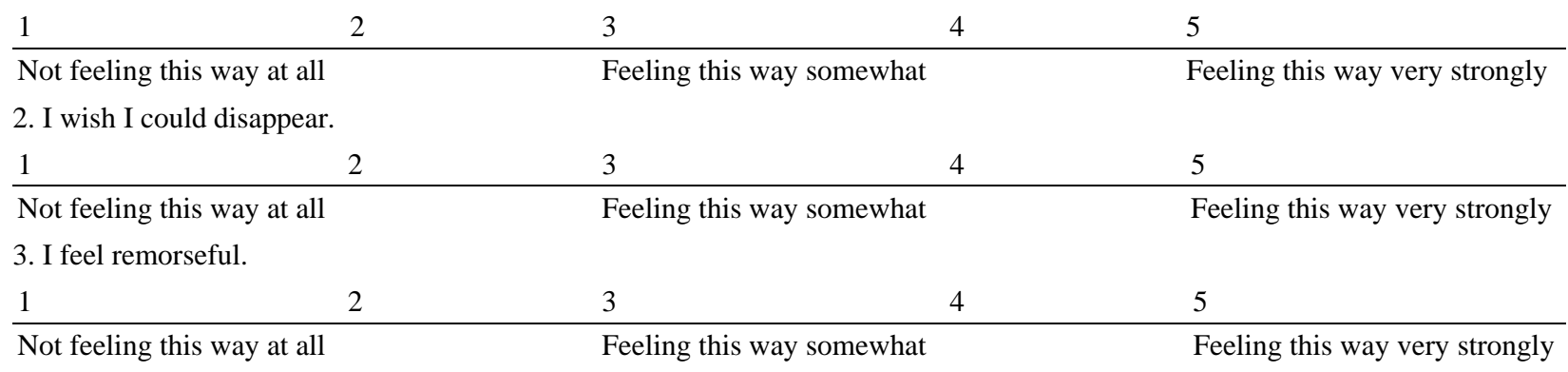

4. I feel that I am of little value.

\begin{tabular}{llll}
1 & 2 & 3 & 4 \\
\hline Not feeling this way at all & Feeling this way somewhat & Feeling this way very strongly
\end{tabular}

5. I feel tension about something I have done.

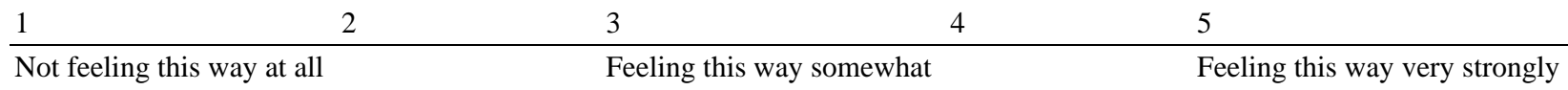

6. I feel like I am a bad person.

\begin{tabular}{llll}
1 & 2 & 3 & 4 \\
\hline Not feeling this way at all & Feeling this way somewhat & Feeling this way very strongly
\end{tabular}

7. I cannot stop thinking about something bad I have done.

\begin{tabular}{|c|c|c|c|c|}
\hline 1 & 2 & 3 & 4 & 5 \\
\hline & & \multirow{2}{*}{\multicolumn{2}{|c|}{ Feeling this way somewhat }} & Feeling this way very strongly \\
\hline \multicolumn{4}{|c|}{ 8. I feel proud. } & \\
\hline 1 & 2 & 3 & 4 & 5 \\
\hline
\end{tabular}


9. I feel humiliated.

\begin{tabular}{llll}
1 & 2 & 3 & 4 \\
\hline Not feeling this way at all & Feeling this way somewhat & Feeling this way very strongly
\end{tabular}

10. I feel like apologizing for something bad I have done.

\begin{tabular}{llll}
1 & 2 & 3 & 4 \\
\hline Not feeling this way at all & Feeling this way somewhat & Feeling this way very strongly
\end{tabular}

11. I feel pleased about something I have done.

\begin{tabular}{llll}
1 & 2 & 3 & 4 \\
\hline Not feeling this way at all & Feeling this way somewhat & Feeling this way very strongly
\end{tabular}

12. I feel worthless.

\begin{tabular}{llll}
1 & 2 & 3 & 4 \\
\hline Not feeling this way at all & Feeling this way somewhat & Feeling this way very strongly
\end{tabular}

13. I feel bad about something I have done.

\begin{tabular}{llll}
1 & 2 & 3 & 4 \\
\hline Not feeling this way at all & Feeling this way somewhat & Feeling this way very strongly
\end{tabular}

14. I feel others would treat me differently if they knew about my offense.

\begin{tabular}{llll}
1 & 2 & 3 & 4 \\
\hline Not feeling this way at all & Feeling this way somewhat & Feeling this way very strongly
\end{tabular}

15. I feel like I'm now part of a group of people society looks down upon.

\begin{tabular}{llll}
1 & 2 & 3 & 4 \\
\hline Not feeling this way at all & Feeling this way somewhat & Feeling this way very strongly
\end{tabular}

16. I feel like I can't be loved because of the offense I have done.

\begin{tabular}{llll}
1 & 2 & 3 & 4 \\
\hline Not feeling this way at all & Feeling this way somewhat & Feeling this way very strongly
\end{tabular}

17. I feel that my offense really hurt someone.

\begin{tabular}{llll}
1 & 2 & 3 & 4 \\
\hline Not feeling this way at all & Feeling this way somewhat & Feeling this way very strongly
\end{tabular}

18. I feel sad when I see that other people are sad.

\begin{tabular}{llll}
1 & 2 & 3 & 4 \\
\hline Not feeling this way at all & Feeling this way somewhat & Feeling this way very strongly
\end{tabular}

19. I feel that I understand how another person feels when they are hurt.

\begin{tabular}{llll}
1 & 2 & 3 & 4 \\
\hline Not feeling this way at all & Feeling this way somewhat & Feeling this way very strongly
\end{tabular}

20. I feel that my actions can affect other people.

\begin{tabular}{llll}
1 & 2 & 3 & 4 \\
\hline Not feeling this way at all & Feeling this way somewhat & Feeling this way very strongly
\end{tabular}

\section{Appendix B}

Consent to Participate in a Research Study

Missouri State University

Department of Criminology and Criminal Justice

You have been asked to participate in a research study. Before you agree to participate in this study, it is important that you read and understand the following explanation of the study. The investigator will also explain the project to you in detail. If you have any questions about the study or your role in it, be sure to ask the investigator. If you have more questions later, Aida Hass, the person mainly responsible for this study, will answer them for you. You may contact the investigator at (417) 836-4890. 
You will need to sign this form giving us your permission to be involved in the study. Taking part in this study is entirely your choice. If you decide to take part but later change your mind, you may stop at any time. If you decide to stop, you do not have to give a reason and there will be no negative consequences for ending your participation.

The purpose of this study is to better understand the benefits of employing restorative justice practices such as Victim Impact Panels (VIP) in the use of intervention methods on juvenile offenders. This study will consist of a pre-test questionnaire administered to you prior to participating in the VIP. There will be a post VIP completion interview with each participant. The benefit of your participation will be to improve the delivery of juvenile justice intervention and improve the administration of programming.

There are no risks involved in this study. The results of this study are confidential and only the investigators will have access to the information which will be kept in a locked facility at the University. No personal identifying information will be used at any time. Your identity will remain anonymous.

Consent to Participate

I have read and understand the information in this form. I have been encouraged to ask questions and all of my questions have been answered to my satisfaction. By signing this form, I agree voluntarily to participate in this study. I know that I can withdraw from the study at any time.

Participant Signature Date Parent/Guardian Signature Date

Printed Name of Participant Printed Name of Parent/Guardian

Signature of Person Obtaining Date 